\title{
UV and Gamma Irradiation Effects on Surface Properties of Polyurethane Derivate from Castor Oil
}

\author{
Elaine C. Azevedo, Eduardo M. Nascimento \\ Universidade Tecnológica Federal do Paraná, UTFPR \\ Gilberto 0. Chierice, Salvador Claro Neto \\ Instituto de Química de São Carlos, IQSC, USP \\ Carlos M. Lepienski \\ Universidade Federal do Paraná, UFPR
}

\begin{abstract}
Gamma and ultraviolet radiation effects on hardness, elastic modulus and viscoelastic properties of polyurethane derived from castor oil (PU) were investigated by nanoindentation tests. Modifications on surface morphology, induced by radiation, were observed by atomic force microscopy. The polyurethane derivate from castor oil shows good resistance to gamma radiation, with only small changes in hardness, elastic modulus, viscoelastic properties and contact angle. The hardness of PU increases at the near surface region due to UVA radiation and decreases after UVC radiation. The contact angle for water drop decreases after UVC radiation, but not after gamma radiation, despite a significant increase in roughness. Such results are attributed to different responses from polyurethane to radiation energy. Increase in hardness due to UVA is attributed to a higher crosslinking at shallow depths, while a decrease in mechanical properties may be attributed to chain scission. These results are consistent with the modifications on viscoelastic properties. Shore D hardness did not show the same trend as observed by nanoindentation results. Hardness, viscoelastic properties and contact angle of castor oil polyurethane are more severely influenced by UVC radiation, while gamma radiation does not have a significant effect.
\end{abstract}

Keywords: Polyurethanes, castor oil, hardness, gamma radiation, UV radiation, nanoindentation.

\section{Introduction}

The polyurethane derived from castor oil has gained great prominence in the scientific community due to their versatility in obtaining materials with different mechanical, physical and chemical properties. In addition to this versatility polyurethanes derived from castor oil are of renewable raw material that does not use volatile organic compounds in the composition. This polyurethane also has biodegradable characteristics in the presence of microorganisms that degrade fats. These aspects make it an environmentally friendly material to the environment ${ }^{[1]}$. The structure present in this polyurethane also gives properties to be biocompatible with the human body also diversifying its use in the medical field ${ }^{[2,3]}$.

Polymers derived from renewable raw material and which does not use volatile organic compounds in the composition are a current concern, as well as polymers that are biodegradable, which generates less waste. The polymer derived from castor oil meets these goals ${ }^{[3]}$. The Analytic Chemistry and Technology of Polymers Group from USP-São Carlos has developed a different kind of polyurethane, made from castor oil, which is a raw material that is renewable and of natural origin: castor oil is a triglyceride derived from ricinoleic acid, which presents the peculiarity of being one of the few acids whose natural chemical structure possesses three highly reactive functional groups: the carbon, unsaturation in the hydroxyl group in the $12^{\text {th }}$ carbon and the carbonyl group in the $1^{\text {st }}$ carbon $^{[4,5]}$.

The study of the effect of UVC and gamma radiation on the polyurethane derived from castor oil is directly related to its use in medicine, because in this area these types of radiation are widely used in sterilization processes, whereas UVA is always present in the middle due to the presence of fluorescent lamps and solar radiation. Polymer materials subjected to these types of radiation can undergo structural changes losing their properties, and can also release toxic materials, such as the case of solvents. Therefore, this study is of great importance for the development of new materials with application in the medical field.

Radiation-induced crosslinking processes in polymers are well known and are used to improve the properties of some polymers like polyethylene $e^{[6,7]}$ or polysulfone ${ }^{[8]}$. However high levels of radiation cause polymer degradation ${ }^{[9-11]}$. Increase in hardness is observed after gamma and UVA irradiation ${ }^{[2,13]}$. In addition gamma radiation is a widely employed method to sterilize polymer based medical equipments and prosthesis. Ultraviolet (UVC) radiation is also used for decrease bacteria proliferation in some situations, while ultraviolet from solar radiation (UVA - UVB) is an important source of polymer degradation in the nature ${ }^{[14,15]}$.

Corresponding author: Elaine C. Azevedo, Universidade Tecnológica Federal do Paraná - UTFPR, Av. 7 de Setembro, 3165,

CEP 80230-901, Curitiba, PR, Brazil, e-mail: helunica@yahoo.com.br 
Ultraviolet and gamma radiation can increase polymerization, cross-linking or chain scission and to improve surface aging due to oxidation or other chemical reactions at surface. Increase in hardness is mainly observed after irradiation due to these alterations in the surface $^{[16-18]}$.

Surface regions can be affected in a different way than bulk after irradiation, being necessary to investigate the modification of mechanical properties at near surface regions ${ }^{[19]}$. Despite conventional Vickers, Knoop and Brinnell hardness techniques can be used to investigate surface of polymers, the dimensions of the residual impression due indentation vary with the time after unloading ${ }^{[20]}$.

Instrumented indentation is a technique that allows measuring simultaneously the indentation load and displacement into the sample as a function of time. This method permits to control the deformation rate which is an important parameter for analyzing modification in polymer mechanical properties ${ }^{[21,25]}$. Hardness, elastic modulus and the viscoelastic behavior can be investigated by using the adequate choice of indenter geometry and loading rates ${ }^{[23]}$. The technique is well suited for comparative studies, with the advantage to investigate small regions in one or only a few samples. In polymers the mechanical properties are time dependent and an adequate choice of test parameters, as loading and unloading rates, is fundamental to obtain comparable values $^{[22-24]}$.

Investigations of surface effects promoted by radiation are not easily done using tensile or compressive traditional tests. The modifications can be restricted to surface region and the test results show alterations only if a significant part of the sample is modified. The study of mechanical properties of surface region is important in the case of medical applications where the surface is a close contact to the body fluids and can be affected by them, and in some cases the polymer is in contact under high stresses ${ }^{[25]}$.

Viscoelastic properties are commonly investigated by dynamical mechanical analysis (DMA). However when the modifications induced by irradiation occurs mainly at surface, it is necessary to employ adequate technique to investigate modifications at shallow depths. Viscoelastic investigations using instrumented indentation give interesting results in this case. Viscoelastic properties of PU from castor oil composites were investigated by nanoindentation tests using spherical indenters ${ }^{[26]}$.

The effect of gamma radiation on the mechanical properties at surface of polyurethanes derivate from castoroil was previously investigated ${ }^{[27]}$ by nanoindentation. However the effect of UV radiation at surface on this polymer was not yet published.

In this study the effect of gamma and ultraviolet (UVA and UVC) irradiation on the mechanical properties of polyurethanes derivate from castor oil was investigated by nanoindentation technique. This technique is highly sensible to modifications in the mechanical behavior of materials at the near surface region ${ }^{[28]}$. In addition, modifications on surface morphology and contact angle were correlated to irradiation effects on mechanical properties.

\section{Experimental}

The polyurethane was prepared from a polyol synthesized from the castor oil that is a tri-functional polyester, being the ricinoleic acid the principal compound ${ }^{[29]}$. The pre-polymer was synthesized from polyol with diphenylmethane diisocyanate (MDI), keeping a percentage of free isocyanate and hydroxyl radicals, for posterior reaction. The sample was prepared with the addition of pre-polymer and polyol at a 1:1 weight proportion ${ }^{[30]}$. In the Figure 1 it is shown the structure of the ricinoleic acid.

The gamma radiation doses of $25 \mathrm{kGy}$ and $100 \mathrm{kGy}$ were provided for exposition in a MDS Nordion's JS-9600 industrial equipment of Cobalt 60 source, which is employed for sterilization of polymer materials for medical applications.

Ultraviolet radiation, UVA, was provided by a commercial UVA lamp Sylvania 15 W - 350 BL with peak radiation at $350 \mathrm{~nm}$. The samples were put at $40 \mathrm{~cm}$ from the lamp. The exposition time was up to $1440 \mathrm{~h}$. Exposition to UVC radiation was provided by a commercial UVC lamp Phillips - TUV 15W with peak radiation at $253 \mathrm{~nm}$. The samples were put at $40 \mathrm{~cm}$ from the lamp for exposition time up to $1440 \mathrm{~h}$. Lamps with similar configuration were chosen to obtain a better comparative analysis. Although the UV radiation energy incident in the samples was not the same for both lamps.

Instrumented indentation was employed to measure hardness $(\mathrm{H})$ and elastic modulus $(\mathrm{E})$ by using the Oliver and Pharr method ${ }^{[28,31]}$. The applied loads vary from 0.1 to $400 \mathrm{mN}$. Indentations were made using a Nanoindenter $\mathrm{XP}^{\mathrm{TM}}$ from MTS Systems with a Berkovich indenter, by multiple loading-unloading nanoindentation tests at increasing loads in the same indentation point.

Bragg- Brentano X-ray diffractograms were obtained from a Shimadzu XRD 7000, $\mathrm{Cu} \mathrm{K \alpha}, 40 \mathrm{KV}, 20 \mathrm{~mA}$. Atomic force microscopy, in contact mode, employed to investigate the modifications in the polymer surface after irradiation. The scanning area was $30 \mu \mathrm{m} \times 30 \mu \mathrm{m}$. The images were obtained with a SPM-9500 equipment from Shimadzu. Shore D hardness tests were carried out in a Wutest Shore D model MP-2a, at room temperature, following the procedure described by ASTM D 2240-75. For each type of sample, tests were performed in triplicate, applying the probe in different sample regions and calculate the average value. The contact angle measurements were performed with a Tantec Contact Angle Meter.

It was supposed that Burgers linear viscoelastic model can be applied to this PU if the applied stress is low enough. The viscosity measurements were made

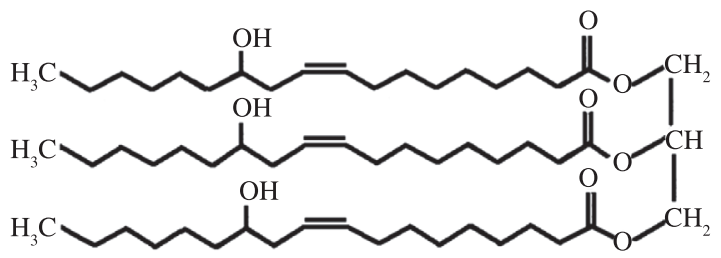

Figure 1. Structure of ricinoleic acid molecule. 
using instrumented indentation, with a spherical tip of $150 \mu \mathrm{m}$ radius. Increasing loads were applied in $5 \mathrm{~s}$ and maintained constant for time intervals equal to $400 \mathrm{~s}$, following 6 steps, each one with loads twice the previous load. Viscosity was investigated from penetration drift rates measured by $\mathrm{dh}^{3 / 2} / \mathrm{dt}$ derived in the last $100 \mathrm{~s}$ of each loading step following the procedure described by Azevedo ${ }^{[26]}$.

\section{Results}

Comparative Bragg- Brentano X-ray diffractograms for irradiated samples and the original unirradiated polymer are shown in the Figure 2. The curves for irradiated samples were translated for higher intensity values, by addition of fixed amounts, for better visualization. The diffracttogram curves are similar, indicating that only small changes in the structure resulted from irradiation. The samples continue to present an almost amorphous structure after irradiation. After UVC and UVA radiation it is observed a shift to lower Bragg's diffraction angle for the more intense peak, indicating an increase in the

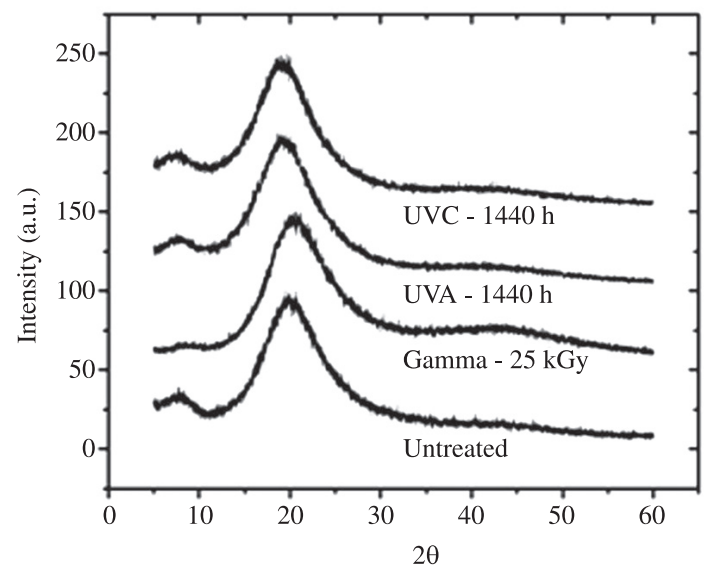

Figure 2. Bragg- Brentano X-ray diffractgrams for original polymer and after gamma (25 kGy), UVC (1440h), and UVA (1440h) irradiation.

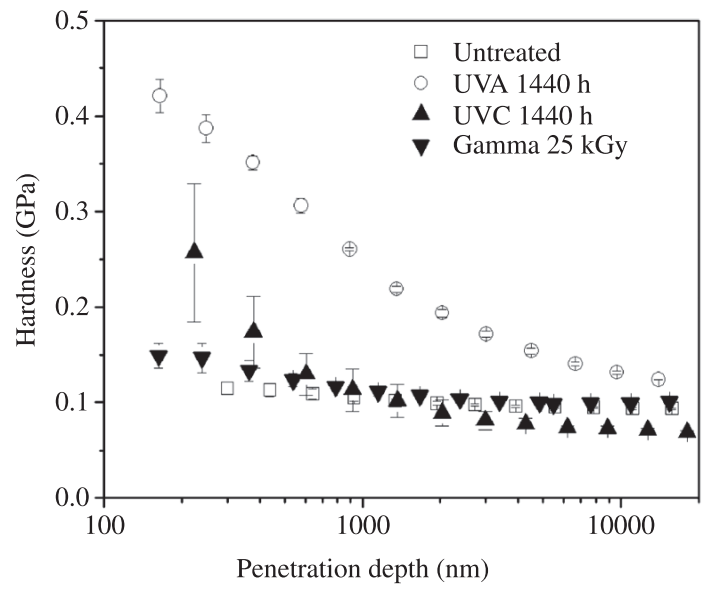

Figure 3. Hardness as a function of penetration depth for different conditions of irradiation. distance between chain layers. After gamma irradiation it is observed a decrease on the intensity of the peak at $8^{\circ}$ and a new, small intensity, peak around $43^{\circ}$. In addition, the more intense peak is shifted to higher diffraction angle.

According to Trovati et al. ${ }^{[32]}$ and Yang ${ }^{[33]}$ the broad peak at $20^{\circ}$ corresponds to regular interplanar spacing corresponding to aromatic rings from MDI. A decrease in intensity of the peak at $8^{\circ}$ and a change in the position of the peak at $20^{\circ}$ indicating a decrease in the chain spacing. In opposition the UVC promotes a shift to lower angles for this peak, corresponding to an increase in d-spacing, probably due to chain scission.

The hardness values as a function of penetration depths are shown in Figure 3. Untreated polyurethane shows a hardness of about $0.10 \mathrm{GPa}$ for penetration depths varying from $500 \mathrm{~nm}$ to $12000 \mathrm{~nm}$ being only a slightly higher at shallow depth penetrations. The samples irradiated with gamma rays with a dose $25 \mathrm{kGy}$ present an increase in hardness to values of $0.13 \mathrm{GPa}$ at a depth of $500 \mathrm{~nm}$. At tip penetration depths of about $5000 \mathrm{~nm}$ the measured value is $0.11 \mathrm{GPa}$.

UVA irradiation causes a significant increase in hardness at near surface region compared to unirradiated sample. The hardness values obtained from nanoindentation for UVA irradiated sample was $0.38 \mathrm{GPa}$ for tip penetrations of $250 \mathrm{~nm}$. If the indenter tip penetrates $10000 \mathrm{~nm}$ the measured hardness is about $0.15 \mathrm{GPa}$. This value is still $50 \%$ higher than the obtained for the unirradiated polymer at same tip penetrations. After UVC irradiation hardness increases to $0.25 \mathrm{GPa}$ at near surface region but decreases to $0.06 \mathrm{GPa}$ at deeper penetrations.

Figures 4a-d shows the atomic force microscopy images of untreated and irradiated samples. The surface morphology is modified by the irradiation. Roughness does not change significantly with UVA radiation while UVC causes a small increase in roughness.

The $R_{a}$ roughness of untreated sample (Figure $4 a$ ) was $12 \mathrm{~nm}$. In the UVA irradiated sample is possible to observe a decrease in roughness being $R_{a}=5 \mathrm{~nm}$, but the sample is less homogeneous. The increase in hardness and a decrease in roughness indicated a higher level of chemical bonds at surface, that can be associated to a crosslinking and/or oxidation induced by UVA radiation. UVC promotes a more severe modification in morphology, increasing $\mathrm{R}_{\mathrm{a}}$ to $65 \mathrm{~nm}$. The chain scission is the most probable cause, as the hardness decreases for deep penetrations, since UVC penetrates deeper in the polyurethane surface. The most pronounced modifications in surface morphology are observed after gamma irradiation. In this sample the measured $\mathrm{R}_{\mathrm{a}}$ was $125 \mathrm{~nm}$ with longer range waviness. This effect is in agreement with the modification in the X-ray diffraction pattern that indicates a more intense change in chain spacing respect to untreated sample.

Nanoindentation tests also permits to determine the elastic modulus ${ }^{[28]}$. The measured elastic modulus of polymer materials with this technique is dependent of loading rates. Considering the tests were comparative a clear increase in elastic modulus is observed at surface 


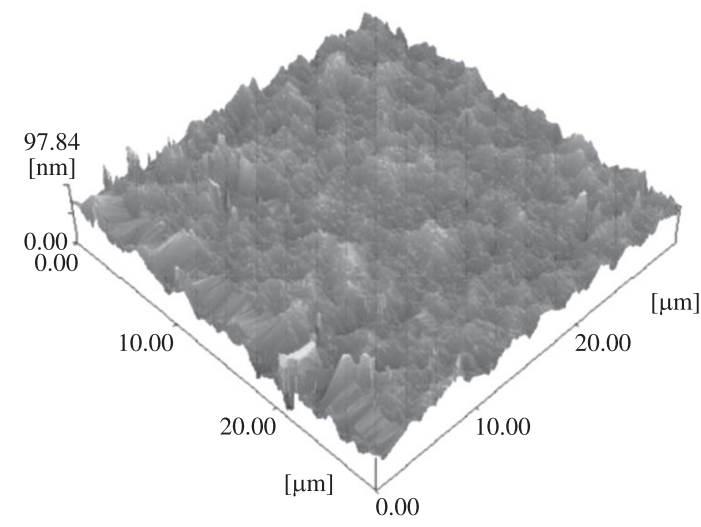

(a)

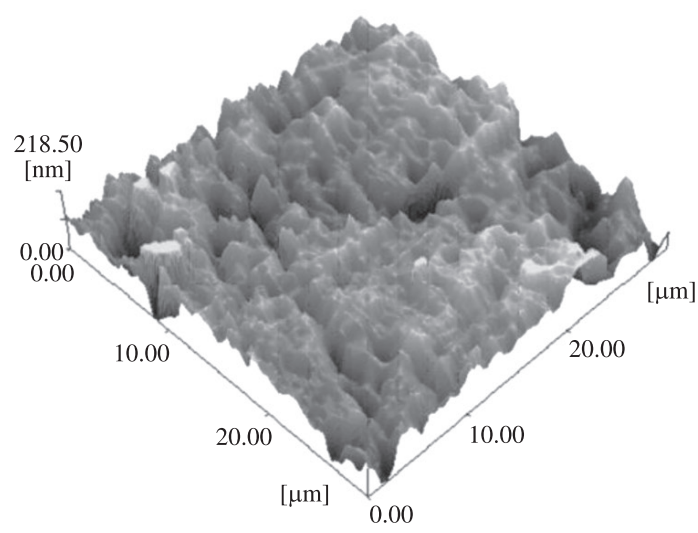

(c)

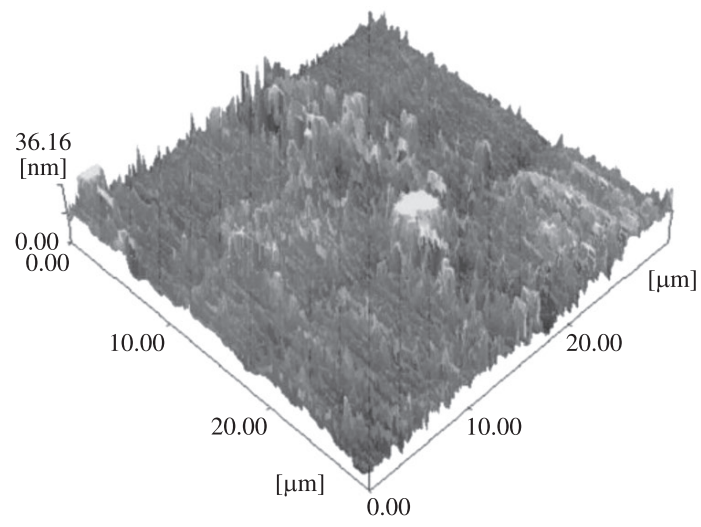

(b)

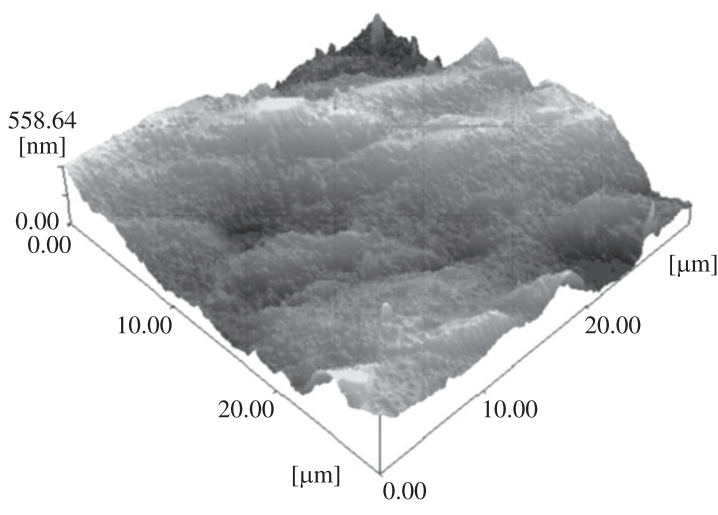

(d)

Figure 4. Atomic Force Microscopy images for (a) untreated sample, (b) UVA irradiated, (c) UVC irradiated and (d) 25 kGy dose gamma irradiated samples. Each image has a different $\mathrm{z}$ scale.

in Figure 5 for UVA irradiated samples. This high elastic modulus, at near surface indicates that the allowed deformations in the surface layer are lower than for the bulk at same stresses. Then high tensile stresses at surface region may appear when the sample deforms as a whole. Under tensile stresses this hard and stiff layer can not accommodate the deformation and cracks may occur in the surface region, as observed by scanning electron microscopy in the Figure 6. In gamma and UVC irradiated samples cracks were not observed at surface.

The results for contact angle are shown in Figure 7 in function of UV aging time and gamma radiation dose.

UVC irradiation causes a decrease in contact angle for water drop after irradiation. UVA irradiation causes only a slight decrease in contact angle even for long time exposure.

Table 1 shows the values of Shore D hardness. The unirradiated sample shows the lower value, while the sample gamma irradiated by $100 \mathrm{~h}$ shows the higher values. Comparing these results with nanoindentation hardness it is verified that gamma radiation does not promotes a higher modification of hardness values at near surface but influences the Shore D hardness. It implies a more deep modification induced by the high penetration

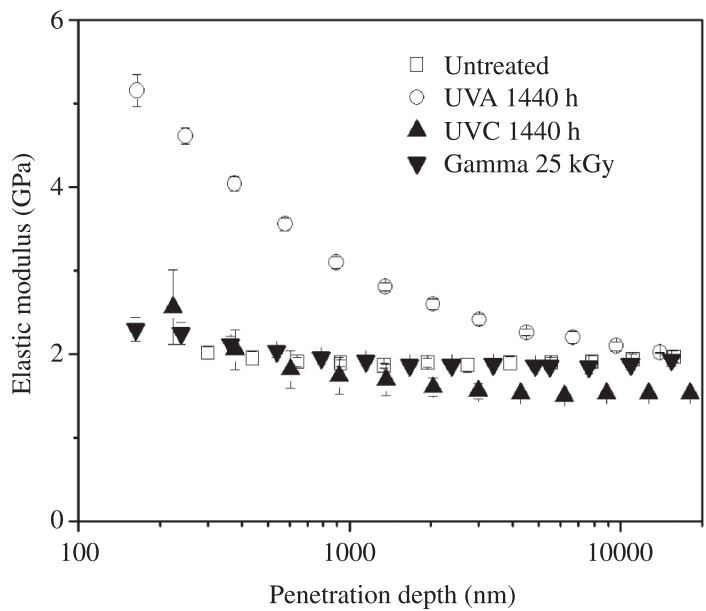

Figure 5. Elastic modulus as a function of penetration depth for gamma and ultraviolet irradiated sample compared to untreated sample.

of gamma radiation. UVC sample shows a Shore D hardness similar to the untreated sample, but at surface region occurs a significant decrease in hardness. UVA radiation promotes a consistent increase in hardness at 


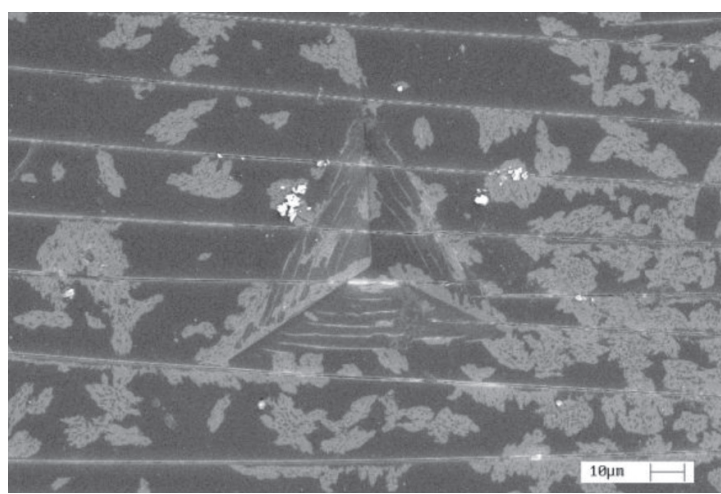

Figure 6. Scanning electron microscopy of an indentation on a 1440h UVA irradiated sample showing the cracks at the surface.

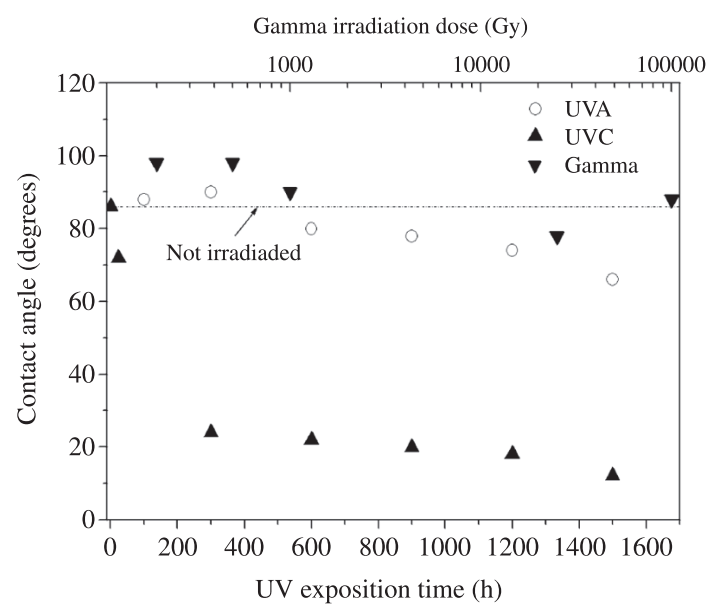

Figure 7. Contact angle as function of UV aging time and gamma radiation dose.

Table 1. Shore D hardness of Castor oil polyurethane for irradiates and unirradiated samples.

\begin{tabular}{lc}
\hline Radiation & Shore D Hardness \\
\hline UVA-1440 h & $74,2 \pm 0,4$ \\
UVC-1440 h & $70,4 \pm 0,8$ \\
Gama 1 kGy & $73,4 \pm 0,5$ \\
Gama 25 kGy & $75,0 \pm 0,6$ \\
Gama 100 kGy & $77,0 \pm 1,4$ \\
Unirradiated & $70,0 \pm 0,7$ \\
\hline
\end{tabular}

shallow depths and considering bulk effects as shown by Shore D hardness values.

The apparent viscosity was determined from spherical indentation with multiple step loading of $5 \mathrm{~s}$ loading followed by 400s of load holding in each load. The next load was always double of the precedent values.

The applied loads used for viscosity calculation were determined to avoid viscoplasticity in the samples. The maximum stress under the spherical indenter was lower than $1 / 3$ of the hardness, considering the limit for yield stresses.

Consider a material that can be described by the four parameters viscoelastic model. An indentation test by step loading with a spherical indenter of radius $\mathrm{R}$ generates a time dependent response for the penetration, h, given by

$$
h^{3 / 2}(t)=\frac{3}{4} \frac{F_{0}}{\sqrt{R}}\left[\frac{1}{E_{1}^{*}}+\frac{1}{E_{2}^{*}}\left(1-e^{-t E_{2}^{*} / \eta_{2}}\right)+\frac{1}{\eta_{1}} t\right]
$$

In this equation $F_{0}$ is the applied load, $E^{*}{ }_{1}$ is the reduced elastic modulus relative to instantaneous elastic deformation, $E_{2}^{*}$ is the reduced elastic modulus related to delayed elastic deformation, $\eta_{2}$ is the viscosity response of the dashpot related to delayed elasticity, with time constant $\eta_{2} / E^{*}$, and $\eta_{1}$ is the long term viscosity.

The reduced modulus $\mathrm{E}^{*}$ is given by

$$
\frac{1}{E^{*}}=\frac{\left(1-v^{2}\right)}{E}+\frac{\left(1-v_{i}^{2}\right)}{E_{i}}
$$

where $\mathrm{E}$ and $v$ are the elastic modulus and the Poisson coefficient of the material and $\mathrm{E}_{\mathrm{i}}$ and $v_{\mathrm{i}}$ are the respective values for the indenter. In the case of indentation in polymers with spherical indenters, the contribution of the term correspondent to the indenter is much lower than the contribution of term from the polymer. Then

$$
E^{*}=\frac{E}{\left(1-v^{2}\right)}
$$

In Eq. 1 the viscosity $\eta_{1}$ is related to long term viscosity in the four elements model. The derivative of equation 1 respect to time, for times much higher than the time constant $\eta_{2} / E^{*}{ }_{2}$ is

$$
\frac{d h^{3 / 2}}{d t} \approx \frac{3}{4} \frac{P_{0}}{\sqrt{R}} \frac{1}{\eta}
$$

Then the viscosity parameter considering times much higher than $\eta_{2} / \mathrm{E}^{*}{ }_{2}$ is given by:

$$
\eta=\frac{3}{4} \frac{P_{0}}{\sqrt{R} \frac{d h^{3 / 2}}{d t}}
$$

The viscosity of all samples was determined from the $\mathrm{dh}^{3 / 2} / \mathrm{dt}$ calculated in the last $100 \mathrm{~s}$ of each step loading, as indicated in the Figure 8 for the unirradiated sample ${ }^{[26]}$.

In the Table 2 are shown the values for the calculated apparent viscosity. It shows a variation of about 10 times between the UVA, more viscous, and UVC the less viscous sample. Gamma radiation induces only a small modification of viscosity at penetrations lower than $5 \mu \mathrm{m}$.

High energetic gamma radiation has high penetration. At the surface a significant increase in roughness observed with a slightly increase in hardness. $X$ ray diffraction indicates a decrease in $\mathrm{d}$-spacing corresponding to a lower distance between aromatic rings from MDI, and an increase in low distance order associated to the increase of the peak at $43^{\circ}$. These effects indicate an increase in the crosslink that promotes increase in hardness. On the other hand ultraviolet radiation has intense effects at near surface regions due to intense absorption by the polyurethane chains. Crosslinking and oxidation is suppose to occur with UVA radiation, while under UVC radiation chain scission occurs being the major effect that decrease hardness at higher penetration depths, while at near surface region an oxidation after chain scission can be the cause of the increase in hardness. 


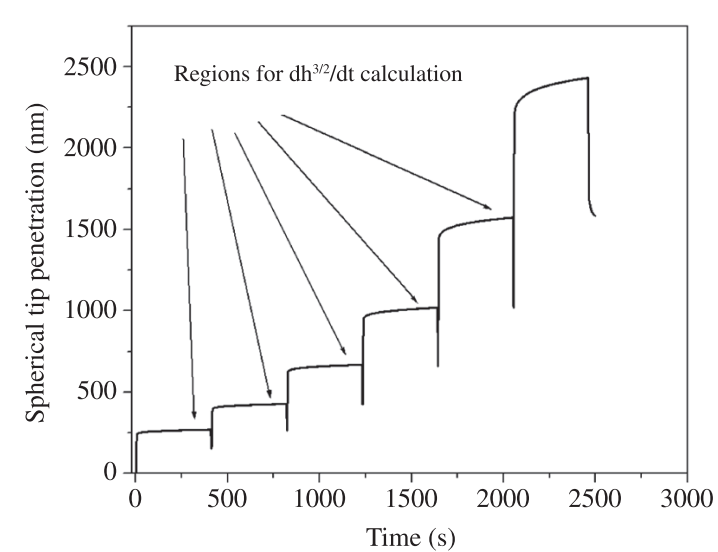

Figure 8. Penetration as a function of time for the unirradiated sample during multiple step loading with spherical indenter of $150 \mu \mathrm{m}$ radius.

Table 2. Apparent viscosity at surface for a $150 \mathrm{~mm}$ radius spherical indentation until penetration depths of $\sim 3 \mathrm{~mm}$, measured from instrumented indentation using multiple loading steps.

\begin{tabular}{cc}
\hline Radiation & Apparent Viscosity (Pa.s) \\
\hline UVA-1436h & $(19 \pm 0,2) \times 10^{12}$ \\
UVC-1491h & $(1.8 \pm 0,2) \times 10^{12}$ \\
Gama 25 kGy & $(9.9 \pm 0,3) \times 10^{12}$ \\
Gama 100 kGy & $(11 \pm 0,1) \times 10^{12}$ \\
Unirradiated & $(9.4 \pm 0,1) \times 10^{12}$ \\
\hline
\end{tabular}

\section{Conclusions}

Polyurethane derivate from castor oil has good aging resistance to gamma radiation. At gamma irradiation dose employed for sterilization the hardness at high penetration present a small increase due to crosslinking. Hardness and elastic modulus increase at the surface due to UVA radiation that attributed to crosslinking and oxidation. After UVC radiation the hardness and elastic modulus decreases for high penetration depths probably due to chain scission. Roughness present a slightly decrease after UVA radiation. Gamma and UVC radiation cause an increase in roughness, with longer distance waviness for gamma irradiation.

\section{Acknowledgements}

We would like to thanks to Cequil-Araraquara - Brasil for providing the PU, the Brazilian agency CNPq for the financial support.

\section{References}

1. Cangemi, J. M.; Santos, A. M.; Claro Neto, S. \& Chierice, G. O. - Polímeros, 16, p.120 (2006).

2. Chierice, G. O.; Azevedo, P.; Freire, V.; Guerios, G. \& Chierice, G. - Rev. Bras. Implantol., 6, p.8 (1997).

3. Ignacio, H.; Mazzer, N.; Barbieri, C. H. \& Chierice, G. O. - Rev. Bras. Ortopedia, 32, p.815 (1997).

4. Cangemi, J. M.; Santos, A. M. \& Claro Neto, S. - Quim. Nova Esc., 31, p.159 (2009)
5. Cangemi, J. M.; Santos, A. M. \& Claro Neto, S. - Quim. Nova Esc., 32, p.3 (2010).

6. Rouif, S. - Radiat. Phys. Chem., 71, p.525 (2004).

7. Mumtaz, T.; Mannan, K. M.; M. R. \& Khan, M. R. - Int. J. Polim. Mat., 59, p.73 (2010). http://dx.doi. org/10.1080/00914030903192377

8. Furtado, A. A.; Gomes, A. S.; Lopes, L. \& Benzi, M. R. - Polímeros, 21, p.137 (2011)

9. Pierpoint, S.; Silverman, J. \& Al-Sheikhly, M. - Radiat. Phys. Chem., 62, p.163 (2001). http://dx.doi.org/10.1016/ S0969-806X(01)00434-0

10. Furtado Filho; A. A. M. \& Gomes, A. S. - Int. J. Polim. Mat., 59, p.424 (2010).

11. Alves, A. S.; Nascimento, L. F. \& Suarez, J. C. - Polímeros, 14, p.105 (2004).

12. Basfar, A. A. - Radiat. Phys. Chem., 50, p.607 (1997). http://dx.doi.org/10.1016/S0969-806X(97)00123-0

13. Salleh, N. G.; Yhaya, M. F.; Hassan, A.; Bakar, A. A. \& Mokhtar, M. - Int. J. Pol. Mat., 58, p.384 (2009).

14. Gonzalez, M. E.; Lunati, C.; Floccari; M. \& Salmoral, E. M. - Int. J. Pol. Mat., 58, p.129 (2010).

15. Fiori Júnior, J.; Piletti, R.; Barichello, T.; Mara, G.N.; Riella, G.; Angioletto,E.; Silva, L. \& Fiori, M. A. - Macromec. Symp., 299-300, p.26 (2011).

16. Maxwell, R, Chambers, D.; Balazs B; Cohenour, R. \& Sung, W. - Polym. Degrad. Stab., 82, p.193 (2003). http:// dx.doi.org/10.1016/S0141-3910(03)00190-3

17. Charlesby, A. - "Atomic radiation and polymer", Pergamom Press, London (1960).

18. Salleh, N. G. N.; Yhaya, M. F.; Hassan; A.; Bakar, A. A. \& Mokhtar, M. - Int. J. Polym. Mat., 58, p.422 (2009).

19. Charlesby, A. - Nucl. Instr. Meth. Phys. Res. B, 105, p.1217 (1995).

20. Baltá-Calleja, F. J. \& Bassett, D. C. - J. Polym. Sci.: Polim. Symp., 58, p.57 (1998).

21. Chien-Kou, L.; Sanboh, L.; Li-Pin, S. \& Nguyen, T. - J. Appl. Phys., 100, p.3503 (2006).

22. Feng, G. \& Ngan, A. H. N. - J. Mater. Res., 17, p.660 (2002). http://dx.doi.org/10.1557/JMR.2002.0094

23. Mencik, J. - Meccanica, 42, p.19 (2007).

24. Oyen, M. L. - Acta Mater., 55, 3633 (2007). http://dx.doi. org/10.1016/j.actamat.2006.12.031

25. Kurtz, S. M. S. M, Muratoglu, O.; Evans, M. \& Edidin, A. A. - Biomaterials, 20, p.1659 (1999). http://dx.doi. org/10.1016/S0142-9612(99)00053-8

26. Azevedo, E. C.; Claro Neto, S.; Chierice, G. O. \& Lepienski, C. M. - Polímeros, 19, p.336 (2009).

27. Azevedo, E. C.; Chierice, G. O.; Claro Neto, S.; Soboll, D. S.; Nascimento, E. M. \& Lepienski, C. M. - Rad. effect deffec sol, 166, p.208 (2010).

28. Oliver, W. C. \& Pharr, G. M. - J. Mater. Res., 7, p.1564 (1992). http://dx.doi.org/10.1557/JMR.1992.1564

29. Bailey, A. E. - "Industrial oil and fat products", Interscience Publishers, New York (1951).

30. Cangemi, J.M.; Santos, A. M.; Claro Neto, S. \& Chierice, G. O. - Polímeros, 18, p.201 (2008). 
31. Briscoe, B. J.; Fiori. L. \& Pelillo, E. - J. Phys. D - Appl. Phys., 31, p.2395 (1998). http://dx.doi.org/10.1088/00223727/31/19/006

32. Trovati, G.; Sanches, E. A.; Claro Neto, S.; Mascarenhas, Y. P. \& Chierice, G. O. - J. Appl. Polym. Sci., 115, p.263 (2010). http://dx.doi.org/10.1002/app.31096
33. Yang, J. H.; Chun, B. C. \& Chung, Y. C. - Polymer, 44, p.3251 (2003). http://dx.doi.org/10.1016/S00323861(03)00260-X

Received: 20/03/12

Revised: 02/10/12

Accepted: 18/10/12 